\title{
Testimonios y repertorios de memoria de Mujeres Tejiendo Sueños y Sabores de Paz de Mampuján
}

\section{Testimonials and memory repertoires of Mujeres Tejiendo Sueños y Sabores de Pazfrom Mampuján}

\author{
Jokabel del Socorro Ramos Díaz Granados* \\ Universidad del Valle, Cali, Colombia.
}

Recibido: 23 de marzo de 2018 Aprobado: 8 de junio de 2018

DOI: 10.25100/lamanzanadeladiscordia.v13i2.7160

Artículo de investigación

\begin{abstract}
Resumen: En este ensayo se analizan los testimonios de mujeres sobrevivientes al conflicto armado en la subregión de los Montes de María. Se discuten los repertorios de memoria que han desarrollado las integrantes de la asociación Mujeres Tejiendo Sueños y Sabores de Paz de Mampuján, frente al desplazamiento forzado y a los procesos de retorno, así como también el rol que las mujeres han venido desempeñando como sobrevivientes al conflicto armado colombiano. Se realizaron entrevistas entre junio y julio de 2016 a dos de estas mujeres, ambas afrodescendientes. Los testimonios analizados se enfocan en la historia de la comunidad en relación con la violencia y el desplazamiento, a través de los relatos recogidos y de los tejidos como repertorios simbólicos de memoria. Finalmente, se exponen varios de los repertorios de memoria trabajados por la asociación como aporte metodológico a la comprensión crítica y rigurosa del pasado traumático en la práctica de construcción de memoria colectiva para la paz.
\end{abstract}

Palabras clave: testimonio; memoria; repertorios de memoria; conflicto armado; desplazamiento; Mampuján.

Abstract: This essay analyzes testimonies by women survivors of the armed conflict in the Colombian Northern Coastal region, Montes de María. It discusses symbolic repertories of memory that members of the Mampuján women association have developed against forced displacement and the process of return, as well as the role that women have been playing as survivors of the Colombian armed conflict. Interviews were conducted with two women of African descent in the community of Mampuján, between June and July 2016. Testimonials focused on the history of the community of violence and forced displacement, through oral stories and tapestries as symbolic repertoires of memory. Finally, several of the memory repertoires worked by the Collective of Mujeres Tejiendo Sueños y Sabores de Mampuján are exposed as a methodological contribution to the critical and rigorous understanding of traumatic past in building collective memory for peace and reconciliation.

Keywords: testimony; repertoires of memory; armed conflict; forced displacement; Mampuján.

Este artículo hace parte del trabajo de tesis de grado: "Testimonios de transformaciones de subjetividad femenina y relaciones de género en procesos de retorno por desplazamiento forzado en dos casos de asociaciones de mujeres de la subregión de los Montes de María".

* Jokabel Del Socorro Ramos Díaz Granados. Licenciada en Historia y candidata a doctorado en humanidades Línea en estudios de Genero de la Universidad Del Valle; "su tesis doctoral se enfoca en testimonios acerca de los procesos de desplazamiento y retorno de las asociaciones de mujeres en Montes de María". Ha trabajado como docente en Cali. Trabaja en programas de políticas públicas con la Subsecretaría de Género y la Ruta Pacífica de Mujeres en la implementación de Atención para Mujeres víctimas de violencia. Actualmente adelanta un proyecto con la Organización Mundial de la Salud sobre salud y experiencias de vida de mujeres marginadas en Cali. Correo electrónico: jokita64@hotmail.com. 


\section{Introducción}

El 10 de marzo del 2000 grupos paramilitares llegaron al corregimiento de Mampuján, una pequeña población de campesinos afrodescendientes situada en el norte de Colombia, más precisamente, en la subregión de los Montes de María, entre los departamentos de Sucre y Bolívar, a menos de dos horas de Cartagena de Indias. Los hombres armados traían una sentencia de muerte colectiva que terminó por desplazar a más de 300 familias (Verdad abierta, 2015).

Una de las mayores consecuencias del desplazamiento ha sido la violación sistemática de los derechos de la comunidad que incluye sus derechos individuales y colectivos, lo que se manifiesta en el daño al tejido organizativo, así como también en la capacidad de producción económica de sus proyectos de vida. En esos contextos de conflicto armado, el testimonio se convierte en una forma de denunciar lo vivido y las iniciativas de memoria, en focos de resistencia.

Los trabajos de memoria que realiza la Asociación de Mujeres Tejiendo Sueños y Sabores de Paz de Mampuján, conformada por mujeres sobrevivientes del conflicto armado, se inscriben en la construcción de la memoria colectiva, superación de traumas y la recuperación del tejido social de la comunidad. En este ensayo se analizan los testimonios de dos mujeres de esta colectividad, recogidos en entrevistas realizadas entre junio y julio del 2016 , y los tapices que han utilizado como repertorio de memoria y de supervivencia.

Este estudio presenta primero, una revisión de literatura en torno al tema del testimonio latinoamericano y femenino en Colombia; para luego enfocarse en los testimonios recolectados de primera mano en la localidad de Mampuján, los cuales revelan las experiencias de vida de las entrevistadas. Las mujeres narran cómo fueron los procesos de adaptación en los nuevos escenarios y sus estrategias de supervivencia durante el desplazamiento forzado y el proceso de retorno. Dichos procesos estuvieron acompañados por un activismo comunitario que exigía la persistencia como compromiso en la búsqueda constante de mejorar no solo sus condiciones de vida, sino las de sus familias y de su comunidad.

\section{Contextualización del testimonio en Latinoamérica}

El testimonio latinoamericano nace de una confluencia de factores que se originan en las coyunturas políticas que vivieron los países latinoamericanos a fines del siglo veinte. El género testimonial nació en el contexto de la revolución cubana con la obra de Miguel Barnet (1966), Biografía de un cimarrón. Pero fue en la década de los ochenta cuando alcanzó su pináculo, con la historia de la líder indígena guatemalteca, Me llamo Rigoberta Menchú y asi me nació la conciencia de Elizabeth Burgos (1984), un relato contado por una mujer indígena de 23 años perteneciente a la etnia maya-quiché, que tuvo el poder de despertar la conciencia de miles de personas en todo el mundo hacia la masacre de grupos indígenas que estaba ocurriendo en Guatemala, por parte del gobierno militar. El relato de Rigoberta Menchú representa no solo su voz, sino la voz de una colectividad marginada en medio de un conflicto armado.

En esa medida, el testimonio se incorporó a los géneros narrativos y en un tipo de discurso aceptado por el canon, pero surgieron muchas preguntas en cuanto a su carácter literario y a la validez como discurso histórico. Por ejemplo, John Beverly, teórico que ha trabajado el tema del testimonio considera que, "la situación del narrador en un testimonio incluye una urgencia por comunicar un problema de represión, pobreza, subalternidad, lucha por supervivencia por parte de una colectividad" (Beverly, 1987, p. 7). Actualmente, los trabajos que se vienen adelantando no se aplican a las luchas revolucionarias del continente, sino a las luchas de supervivencia de víctimas de la violencia, como es el caso de Colombia.

\section{Teoría del testimonio femenino en Colombia}

El testimonio femenino en Colombia se hace presente a partir del 2000 cuando surgen en el país varias obras testimoniales, como el de María Eugenia Vásquez (2000), denominado Escrito para no morir, bitácora de una militancia. En este, la autora deja ver cómo la recuperación de la memoria 
y el acto de la escritura han sido muy significativos, ya que su testimonio autobiográfico se ha convertido en un notable ejercicio etnográfico. El texto muestra la historia contada desde adentro, a través de su testimonio. En dicho testimonio, no existe un mediador y no se trata solo del testimonio de una mujer, sino que es el de muchas mujeres que se representan a través de una narradora en primera persona.

Otro ejemplo sobre la forma en que se construyen las diversas expresiones en torno al testimonio femenino en Colombia lo brinda Carmiña Navia (2005) en Guerra y paz en Colombia, las mujeres escriben. En esta obra, la autora examina primero las particularidades de estas voces y segundo, los contenidos de las propuestas y el género discursivo en el cual se encuentran inscritas. Desde esa perspectiva, Navia señala que las mujeres no solo han dicho su palabra en medio de esta guerra, sino que han hecho propuestas concretas y han señalado posibles caminos para la paz a partir de la práctica etnográfica. Sin embargo, esta palabra ha sido casi siempre silenciada e ignorada. A través de sus interpretaciones sobre el tema, esta autora insiste en afirmar que la expresión femenina se manifiesta a través de análisis y estudios académicos, búsquedas literarias, entrevistas en profundidad, reportajes o artículos periodísticos, entre otras formas, especialmente en lo que se refiere al tema de la guerra y la paz en Colombia. En cada caso, esa palabra ha sido "clara y contundente, porque ha surgido en medio del sentir, del sufrir, del trabajar y construir ... es por lo tanto una palabra que nace en medio de la guerra y que mira insistentemente hacia la paz, y que sueña la paz" (Navia, 2005, p. 119).

Por su parte, Elvira Sánchez Blake (2000) en su obra Patria se escribe con sangre, señala que el testimonio representa la memoria discursiva que refleja las presencias, las ausencias, las voces, los silencios y lo visible e invisible detrás de cada historia. Distingue, además, cómo las mujeres al reconstruir la historia por medio de la palabra refuerzan su identidad y adquieren conciencia de su rol en la política, brindándoles la oportunidad de ser parte de un momento histórico que rompe esquemas y permite la transformación a nivel del país (Sánchez Blake, 2000).
En el documento De actores armadas a sujetos de paz: mujeres y reconciliación en el conflicto colombiano también de autoría de Elvira Sánchez Blake (2012), se señala cómo la escritura individual se transforma en colectiva y surge de la urgencia de explicar y analizar los fenómenos y las dinámicas que se evidencian en una sociedad "afectada por una guerra persistente y crónica" (p. 13). En ese sentido y siguiendo a Todorov (2000), la autora ve en la memoria colectiva una vía de "preservación de la memoria individual que proyecta y refleja una colectividad y actúa de igual manera como una presencia de todo aquello que es silenciado o borrado en esa dualidad de memoria-olvido en las que ambas partes, aparecen como componente de un todo" (Sánchez Blake, 2012, p. 13).

En otro de sus artículos, La ruta pacífica de las mujeres: repertorios simbólicos en la búsqueda de paz y reconciliación en Colombia, Elvira Sánchez Blake (2016) indaga sobre las formas estéticas y expresivas que los grupos de mujeres se han apropiado para buscar un camino que conduzca a la paz y reconciliación del país. Se trata de los repertorios simbólicos de la memoria, los cuales representan nuevas iniciativas de memoria que se expresan a través del arte, el activismo y la educación desarrollados por organizaciones de mujeres, que les permiten a su vez, unirse en iniciativas de resistencias en torno a las experiencias de pérdida y dolor como víctimas del conflicto armado. De esta forma, las mujeres han adquirido un poder, un liderazgo y reconocimiento dentro y fuera de sus comunidades como "agentes de cambio, promotoras y como formadoras de las nuevas generaciones (Sánchez Blake, 2016, p. 4).

\section{La memoria como alternativa opuesta al olvido}

La memoria es un fenómeno siempre actual, un lazo vívido en el presente eterno (Nora, 1984). En Colombia, con una producción testimonial emergente, según Constanza López Baquero (2012), la construcción de memoria emblemática exige la responsabilidad social sobre cómo se siguen reconociendo a las víctimas. En el caso de Mampuján, la producción testimonial aparece cinco años después 
de ocurrido el desplazamiento e iniciados los procesos de justicia y reparación, cuando 15 mujeres de la comunidad buscaron ayuda psicosocial y aprendieron la técnica del quilt, que consiste en coser tela sobre tela con colchas de retazos representado en ellas varias de las escenas de su historia colectiva. Reunidas alrededor de su experiencia violenta y sus recuerdos, estas mujeres imprimen en la tela las escenas y con aguja e hilo tejen los actos de la violencia perpetrados contra su comunidad.

La selección de estas actividades responde a una alternativa como función y fuerza opuesta al olvido. La idea de esos actos implica que pueden ser leídos bien sea de manera literal o de manera ejemplar (Todorov, 2000). Según este autor, la diferencia entre la memoria literal y la memoria ejemplar está en que la primera es la encargada de someter el presente al pasado manteniendo vivo el dolor, mientras que la segunda permite usar el pasado con vistas al presente, y aprovechar las lecciones de las injusticias sufridas para luchar contra las que se producen hoy día y separarse del yo para ir hacia el otro (Todorov, 2000).

Para Todorov (2000), el acto de recordar se convierte en una opción frente a una experiencia pasada, Jelin (2002) retoma este concepto cuando expone que este acto se activa en el presente por un deseo o sentimiento unidos a veces a la intención de comunicarla en él: "las memorias en disputa pueden ser orientadas de forma pasiva al guardar la información del pasado en archivos y centros de documentación, textos, museos o activada por el sujeto en acciones orientadas a dar sentido al pasado interpretándolo y trayéndolo al escenario en el proceso de interacción social" (p. 22). Resulta interesante explorar los usos resistentes de la memoria, partiendo de una reflexión acerca del tiempo y sus dimensiones en la que la relación entre pasado, presente y futuro permite ubicar a ésta, no solo como una presencia del pasado en el presente, sino también como una reflexión al pasado y hacia el futuro convirtiendo a la memoria en un elemento decisivo para la acción del presente (Calveiro, 2008).

\section{La memoria en la práctica y experiencia de mujeres tejedoras de Mampuján}

Según la lideresa de la Asociación de Mujeres Tejiendo Sueños y Sabores de Paz de Mampuján, Juana Alicia Ruíz Hernández, en su libro Vivensías (2013), el fortalecimiento de la comunidad y de la organización de Mampuján tienen sus inicios a partir del 2006 en ese año, surge el proyecto desarrollado por la asociación ASVIDAS ${ }^{1}$ denominado "Mujeres Tejiendo Sueños y Sabores de Paz", orientado hacia la práctica de tejer y conversar como estrategia para sanar el trauma dejado por el conflicto armado. Para esta lideresa, el ejercicio del tejido les ha permitido hacer catarsis, reivindicar sus voces antes silenciadas, expresar sentimientos de tristezas y alegrías. De igual manera, estas prácticas colectivas han sido un aporte de las mujeres afrocolombianas de Mampuján a la construcción de la memoria histórica de la subregión de los Montes de María, el Caribe y el país.

El arte en contexto elaborado por estas mujeres representa para ellas no solo una catarsis frente al duelo, sino también una alternativa para salvaguardar la memoria de lo que ha sido el conflicto armado en la subregión de los Montes de María. A diferencia de otros grupos de mujeres víctimas en Colombia, las integrantes de la Asociación Tejedoras de Sueños y Sabores de Paz de Mampuján, expresan a través de estos tejidos sus experiencias de vida. Sus tapices se han convertido en repertorios de memoria que recogen historias que hablan desde la subjetividad de cada mujer que aprendió a desarrollar una mayor capacidad de resistencia, iniciativa y creatividad en la búsqueda de alternativas para enfrentar las adversidades. Al plasmar la historia en tapices, ellos se convierten en un testimonio de muchos mensajes significativos que ilustran la violencia ancestral (la de la esclavitud), violencia reciente, el arraigo a sus tradiciones afrodescendientes, así como a sus creencias, rituales y costumbres. A continuación, se analizan los tapices como repertorios de memoria que ilustran estos mensajes.

1 Asociación para la Vida Digna y Solidaria ASVIDAS, es una organización de 130 grupos comunitarios locales que trabajan en los departamentos de Bolívar, Sucre, Córdoba y la costa caribe, que tiene 2.500 miembros y un equipo de 30 facilitadores voluntarios y que se dedica al desarrollo de iniciativas de paz sostenibles. 


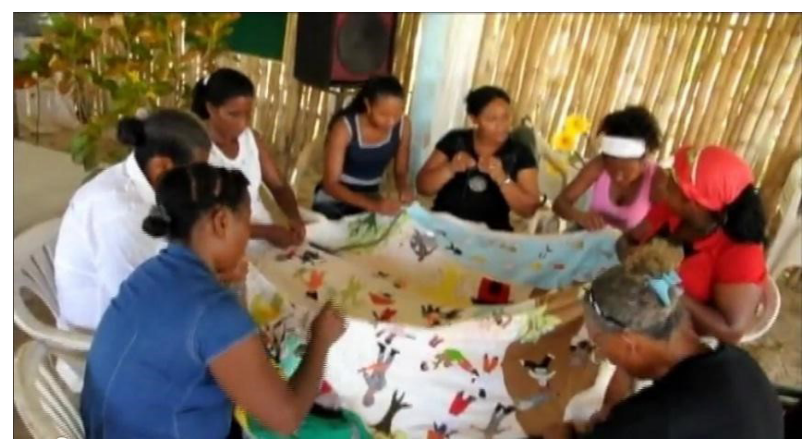

Fotografía 1. Mujeres de Mampuján tejiendo memoria

Fuente: (El Universal, 2017). ${ }^{2}$

\section{Los tejidos como testimonios}

Respecto la importancia que han tenido estos repertorios de memoria en la reconstrucción del tejido social de estas comunidades vale la pena cuestionarse acerca de: ¿Cuál es el tipo de violencia en que se inscriben estos repertorios de memoria? ¿Qué significado tienen los tejidos como testimonio de la cultura? ¿Cuáles elementos de las tradiciones, rituales y culturales se aprecian en los tapices? ¿Cuál ha sido el impacto dejado por estos tapices en la reconstrucción del tejido social dentro de la comunidad? ¿Por qué es importante analizar los tejidos a partir de la memoria ejemplar contemplada en ella? Por último, llama la atención el análisis que se suscita en relación con el tejido como testimonio colectivo, como regenerador de heridas y traumas, como canal de afirmación de identidad de sujetos y transformación de roles hombres que han comenzado a tejer y mujeres lideresas empoderadas y transformadoras de subjetividades.

Según la lideresa Juana Alicia Ruíz, las mujeres no tenían ni voz ni voto. Su deber consistía en hacer de comer y cuidar de los niños y ancianos. En contraste con esto, los hombres eran quienes ejercían el liderazgo y mediaban ante las autoridades y los entes administrativos para obtener las ayudas. En sus propias palabras, sostiene que la experiencia con los tapices ha sido muy importante, porque no solo se han presentado en algunas exposiciones en
Colombia, sino en numerosos escenarios internacionales. Entre ellos se cuentan bibliotecas, galerías de arte, y universidades, tanto de Bogotá, Cartagena, Medellín, Bordeus (Francia), Ginebra (Suiza), Perú y Estados Unidos.

Por algún tiempo, durante el desplazamiento, las mujeres no teníamos ni voz ni voto frente a los asuntos de interés de la comunidad y aunque en algunas ocasiones nos permitían participar en las reuniones, nuestras opiniones nunca eran tenidas en cuenta. Fue entonces, cuando decidimos organizarnos y crear nuestro colectivo. Lo primero en que pensamos fue en buscar una ayuda para sanar nuestra parte emocional, veíamos como muchas mujeres lloraban y sufrían en silencio, lo que indicaba que no habían podido superar el duelo que les había ocasionado el desplazamiento. Por eso acudimos a la fundación Sembrando Paz, para que nos dieran su apoyo (Ruíz, Juana Alicia, comunicación personal, 2016).

En testimonios recogidos por la autora, en junio 2016 en Mampuján Nuevo, las mujeres narran que los primeros tapices que elaboraron iban acompañados de mucho dolor. Cuentan cómo las lágrimas les salían en cada puntada que daban cuando plasmaban en ellos su historia. Sin embargo, reconocen que el tejido se convirtió en instrumento de catarsis, pues a través de él comenzaron a exteriorizar sus sentimientos de tristeza, a sanar los traumas que les dejó conflicto armado y a recuperar la memoria colectiva. Actualmente se han convertido en lideresas comunitarias al empoderarse y apropiarse del reconocimiento de sus derechos como mujeres rurales, afrodescendientes, mestizas y víctimas del conflicto armado. Como resultado de las acciones realizadas por esta asociación, han logrado el reconocimiento de su ser, en tanto sujetos individuales y sujetos colectivos, además de identificarse como mujeres afrodescendientes y campesinas que cosen sus memorias de dolor en diferentes mantas, restaurando así la dignidad y la cotidianidad lacerada por la violencia.

Al igual que las tejedoras de Mampuján, las arpilleras de Chile $^{3}$ ven en el tejido el vehículo para

2 Los derechos de publicación de las fotografías de este artículo han sido cedidos a la revista La Manzana de la Discordia para esta publicación por parte de la entidad editora propietaria del periódico El Universal de la ciudad de Cartagena, Colombia.

3 Grupo de bordadoras activas que transmiten la memoria individual, colectiva y social, mediante mensajes de denuncia, resistencia y relatos de sus vivencias diarias que surgieron después del golpe contra Salvador Allende en 1973, con una temática política y social denunciar eventos que tenían y tienen que ver con la violación de los derechos más elementales, como escenas en las cárceles, comedores populares de las poblaciones, niños y niñas las masacre vivir en la patria como tema de exilio (Agosín, 1985). 
narrar su memoria colectiva. Desde su cotidianidad "transforman sus subjetividades de amas de casa pacientes en activistas sociales creando así una dinámica vital en la historia de su país" (Agosín, pp. 523-524). Lo anterior implica entender la narrativa como un discurso social, vivencial no teórico en el que a través de cada puntada estas mujeres, testimonian lo que la voz no puede exclamar y construyen acciones colectivas como metáfora y analogía del tejido.

Según Agosín (1985), el coser, tejer, bordar, son escrituras femeninas que cuentan lo que la palabra o el habla no pueden decir, al mismo tiempo, estas artes representan escrituras que utilizan el cuerpo mismo como medio de moldear esta expresión: dedos, uñas, brazos. Así, las mujeres que bordan o cosen abandonan el rol tradicional de consumidoras de arte, para convertirse en productoras que trascienden ese orden que las relegó a la marginalidad e incorporarse activamente al proceso de producción de la cultura (Agosín, 1985, p. 524).

Las iniciativas de memoria de las mujeres tejedoras de Mampuján han ayudado a que existan redes de solidaridad no solo entre ellas, sino con otras organizaciones de paz a lo largo y ancho de Colombia, y les ha permitido avances significativos en la recuperación del tejido social en su comunidad y la solidaridad con otras víctimas. Esta ejemplarizante tarea les confirió el reconocimiento del premio $\mathrm{Na}$ cional de Paz $2015^{4}$.

\section{El tejido dentro de las relaciones de género}

Las relaciones de género determinadas al interior de las estructuras del sistema patriarcal establecen dos identidades la masculina y la femenina que legitiman los roles de géneros y crean estereotipos que refuerzan en la práctica cultural la desigualdad entre hombres y mujeres y asignan atributos, características o funciones específicas, únicamente por su pertenencia al grupo social masculino o femenino (OHCHR, 2013). Tales relaciones sociales inscritas al interior de esta forma de organización están condicionadas a relaciones de poder, de dominio sexual, laboral, político y cultural que conducen a formas de cautiverio de las mujeres.

Para Marcela Lagarde, "todas las mujeres están cautivas por el solo hecho de ser mujeres en el mundo patriarcal" (Lagarde, 1997, p. 33). Esta situación de opresión tiene que ver con "el conjunto de características que tienen las mujeres a partir de su condición genérica en circunstancias históricas particulares. En ella, se expresa la existencia concreta de las mujeres particulares a partir de sus condiciones reales de vida" (p.33). Por consiguiente, las condiciones de desigualdad entre las relaciones sociales de género requieren de profundos análisis y de acciones de transformación, puesto que en muchas poblaciones latinoamericanas se siguen fomentando valores y reafirmando comportamientos que actúan deliberadamente en la cotidianidad desvalorizando y discriminando, la mayoría de las veces, las labores asignadas culturalmente a las mujeres.

En oposición a esta perspectiva determinista, las mujeres han venido experimentando cambios en su feminidad, así como también en la estructuración genérica que, a pesar de causar malestar y controversias, las convierte en protagonistas y en ese proceso dejan de ser cautivas (Lagarde, 1997). Para esta autora, en la apertura de este milenio en América Latina los espacios se comienzan a transformar por ejemplo, aquellos que habían sido creados para hombres se tornan mixtos y las mujeres "antes sólo reunidas por segregación patriarcal han fundado otros por voluntad de agregación" (Lagarde, 2012 p. 631).

En esos espacios, diversos movimientos sociales han insistido en la equidad, en que se reconozca que la desigualdad ha sido construida y no es natural, y en la necesidad de realizar acciones afirmativas concretas para lograr la paridad entre mujeres y hombres (Lagarde, 2012).

Los trabajos de memoria que vienen realizando las Mujeres Tejedoras de Sueños y Sabores de Paz de Mampuján a través del tejido se han convertido en acciones afirmativas en las que no solo visibilizan sus experiencias de vida frente al conflicto

4 Premio otorgado por la Organización Premio Nacional de Paz como reconocimiento nacional a un proceso que comenzó hace más de una década, en el cual este grupo de mujeres desplazadas y víctimas de violencia sexual, de ese corregimiento de María la Baja Bolívar (Al norte de Colombia), han plasmado en tapices la violencia que dejaron los paramilitares en los Montes de María entre 1997 y el 2004 (Montaño, 2015). 
armado, sino también el pasado de las comunidades afro en Colombia y los estereotipos de género a los que habían estado sujetas históricamente.

Explorando en esos escenarios de participación política y cultural, estas mujeres han constituido además su liderazgo dentro de su comunidad ${ }^{5} \mathrm{y}$ han logrado que la participación de los hombres en esta labor comience a visibilizarse, ayudando a otros a entender que estos espacios significativos y de acompañamiento, no solo son un medio de catarsis frente al duelo, también son una herramienta para el perdón, la reconstrucción de la memoria colectiva y recuperación del tejido social en la que tanto hombres como mujeres están llamados a cooperar.

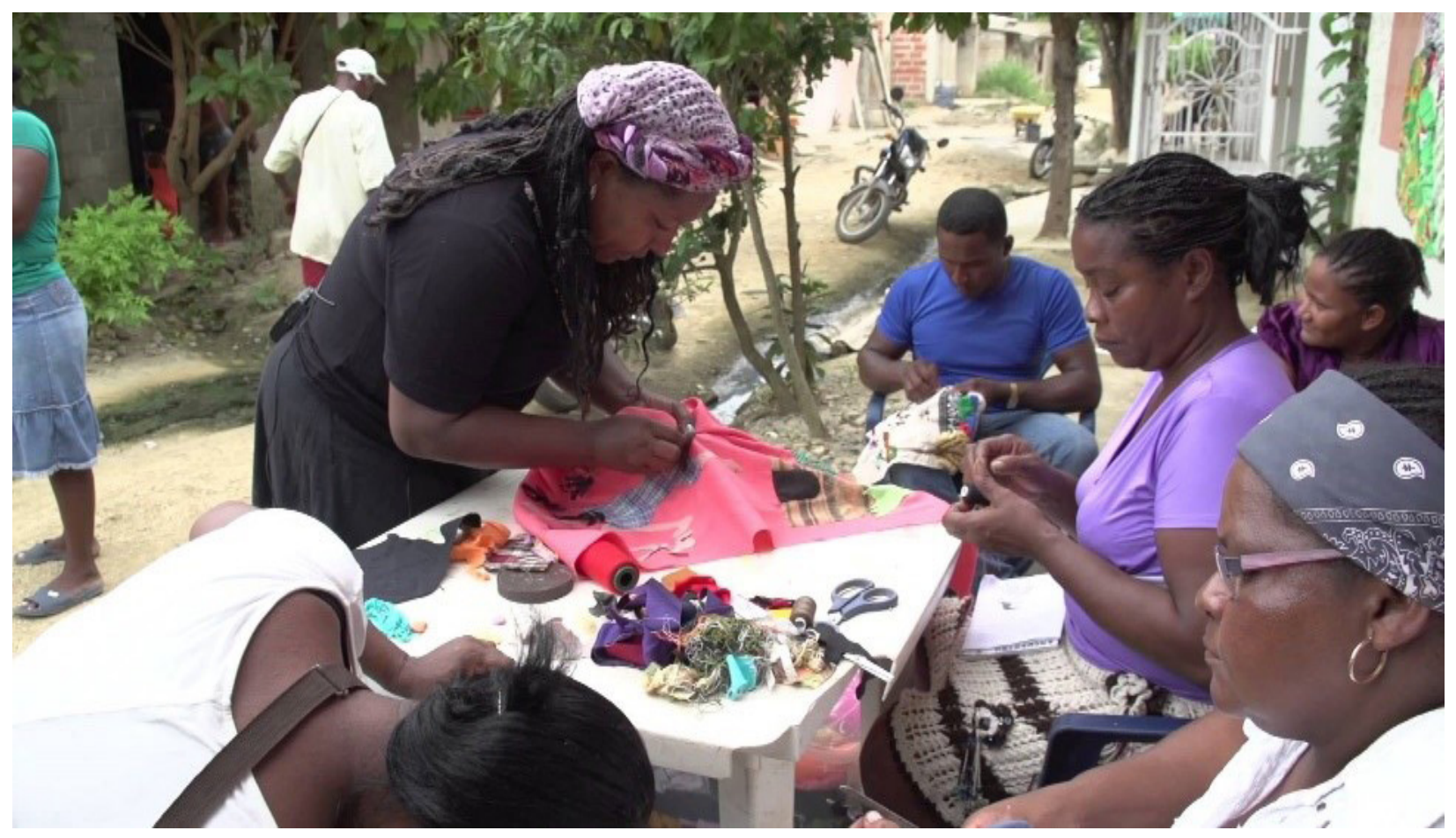

Fotografía 2. Desmontando el patriarcado

Fuente: (El Universal, 2017).

Al comienzo no fue fácil que los hombres participaran en los talleres de memoria, porque estaban muy reacios, muy rebeldes y en realidad poco querían entrar hablar de este tema. Nosotras comenzamos a hablarles y allí las cosas fueron cambiando, tanto así que fue un hombre que terminó públicamente perdonando a un victimario a nombre de la comunidad (Ruíz, Juana Alicia, comunicación personal, 2016).

\section{Tapices como testimonios}

A continuación, se presenta un análisis de siete tapices elaborados por las Mujeres de este colectivo denominados: África Libre, Travesía hacia la esclavitud, Subasta, Día de llanto, Desplazamiento, Masacre en los Montes de María, Hacinamiento y Retorno.

La representación del tapiz titulado "África libre", ilustra la población de África negra como etnia con una tradición ancestral. Se observan las dinámicas sociales que infieren en la construcción de identidades representadas en un linaje que parte de la concepción que tiene la mujer o el hombre africano de no concebirse como un individuo aislado, sino como una prolongación de su ascendencia (Hampâté bâ, 1991). Es importante recordar que en identidades como la afrodescendiente, existe un largo proceso que comienza a partir del momento de la diáspora por el continente americano y su travesía en condición de esclavos y esclavas durante

5 Véase https://colombia2020.elespectador.com/territorio/mampujan-hilando-memoria-y-perdon 
el colonialismo. Del mismo modo, su anclaje ancestral se representa en las expresiones artísticas como la música, los bailes, los ritos espirituales, la gastronomía, traídos por los africanos en condiciones de esclavos y astutamente mimetizados en la cotidianidad de sus vidas en América.

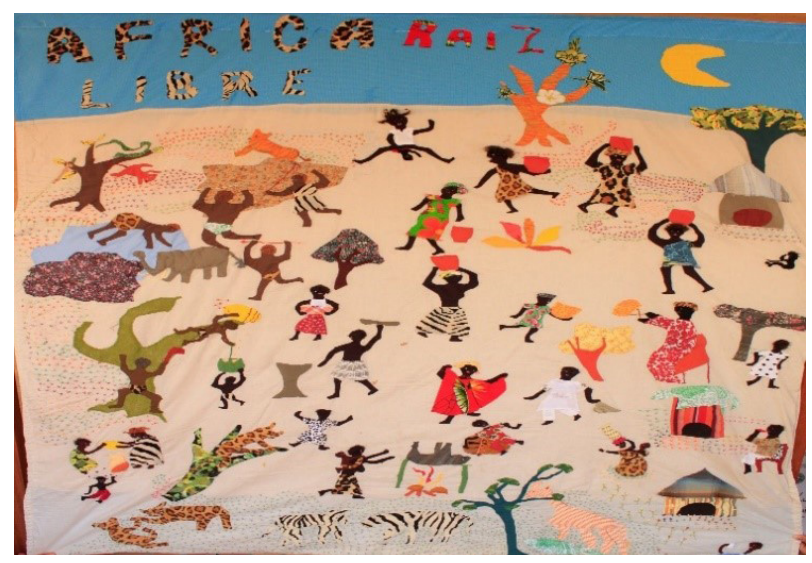

\section{Fotografía 3. Africa Libre: Por las rutas de sus ancestros}

Fuente: (El Universal, 2017).

Recordar la historia de nuestros ancestros es una forma de saber quiénes somos y de dónde venimos. Por eso el propósito al hacer este tapiz consistió en poder visibilizar nuestros orígenes para que las nuevas generaciones conocieran que tenemos unos ancestros y que nuestra resistencia tiene una larga historia. Aquí, los relatos de los abuelos que tenemos en la comunidad fueron de gran ayuda (Ruíz, Juana Alicia, comunicación personal, 2016).

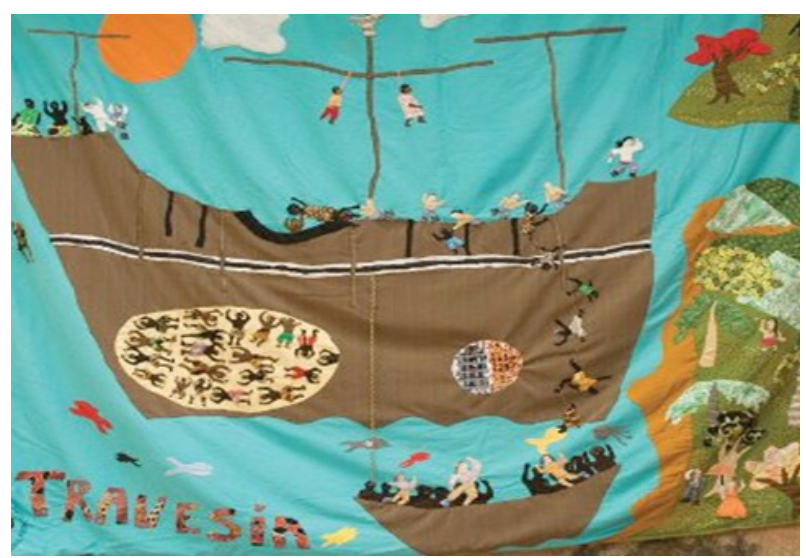

Fotografía 4. Travesía: La ruta hacia la esclavitud Fuente: (El Universal, 2017).
El tapiz llamado "Travesía" es bastante revelador. Evoca la experiencia de muchos africanos perseguidos, torturados y subastados en el comercio de humanos que se gestó al interior del sistema esclavista y que se instauró en América a partir de la implementación del colonialismo. También, pone de manifiesto las relaciones de género expresadas en formas de poder, que según Scott (1986), "fueron construidas en el parentesco, la política, la economía, la identidad subjetiva, la clase, raza y la etnicidad" (p. 47).

Este tapiz que hemos denominado Travesía significa para nosotras el testimonio a la memoria colectiva y muestra la opresión que históricamente vivieron nuestros ancestros durante la esclavitud en América (Ruíz, Juana Alicia, comunicación personal, 2016).

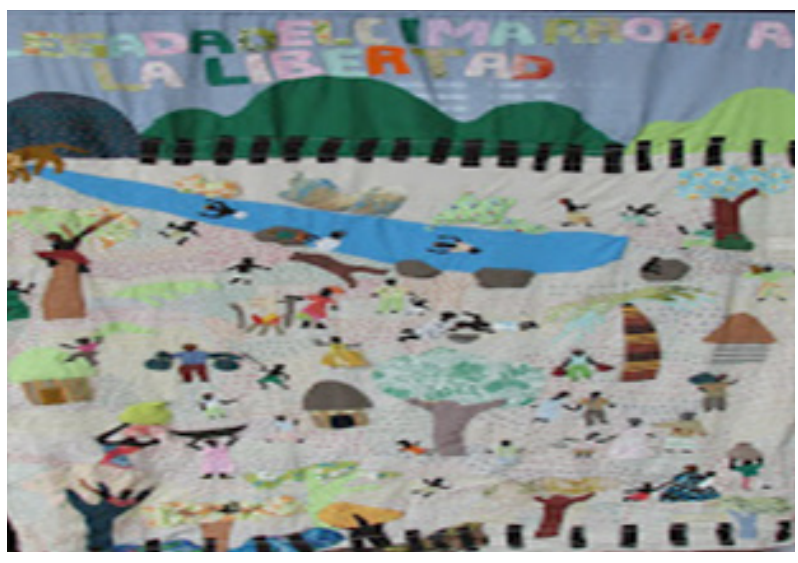

Fotografia 5. Libertad: La huida de la casa del amo al palenque

Fuente: (El Universal, 2017).

Este tapiz titulado "Libertad", no significa una guía para llegar a la felicidad (Moro, 1941) o un valor supremo que está por encima de cualquier otro derecho (Locke, 1999), sino una nueva forma de vida autónoma basada en la figura del palenque. En la costa Caribe colombiana, el Palenque de San Basilio representó la resistencia de un pueblo esclavo. En él, los cimarrones (esclavos rebeldes fugitivos) dieron paso a nuevos pueblos libres del azote del blanco.

Para nosotras, este tapiz lo hemos denominado Libertad y representa un cúmulo de expresiones históricas, sociales y culturales como comunidad 
afrodescendiente, cimarronera así como también el sentido de identidad que acompaña a esta comunidad, pero especialmente, las formas de resistencia social, espiritual y política de libertad de nuestros ancestros, lo que significa, además, el testimonio a la memoria colectiva a la opresión y resistencia que históricamente ha venido acompañando a estas poblaciones (Ruíz, Juana Alicia, comunicación personal, 2016).

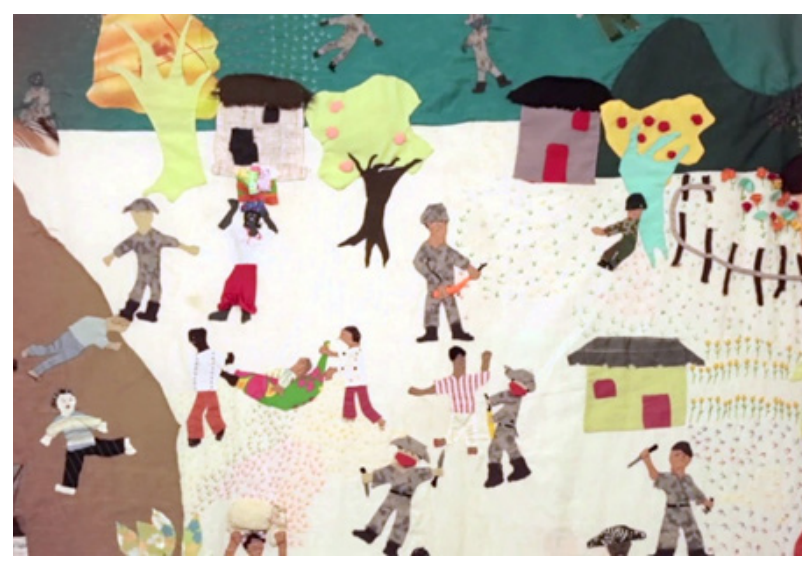

Fotografía 6. Día de Llanto

Fuente: (El Universal, 2017).

El tapiz denominado "Día de llanto", ilustra las expresiones de miedo, incertidumbre, dolor, llanto e ira al interior de un escenario de guerra. Lo ocurrido esa tarde del 10 de marzo del 2000 en el corregimiento de Mampuján bien podría ser la representación en dos actos escénicos: el antes y el después. Dicho tapiz tiene su componente teatral a partir de la historia narrada por las voces de las mujeres del colectivo, quienes evocan la experiencia de vida que les dejó el conflicto armado. Se observa a varios hombres armados y con el rostro tapado intimidando a la población, uno de ellos aplastándole la cabeza a una víctima. Aparecen también, figuras de hombres de la comunidad transportando a un enfermo en una hamaca y a varias mujeres y hombres corriendo y llevando sobre sus cabezas bultos de ropas.

Para nosotras este tapiz tiene un gran significado, porque fue el primero que elaboramos. Lo hicimos como una estrategia de resiliencia para recordar sin ira el dolor de lo ocurrido y sanar nuestro duelo. Tengo que decir que, en cada puntada que dábamos nos soltábamos en llanto y nos íbamos a nuestras casas a llorar, pero después con el tiempo, nos dimos cuenta de que ya no llorábamos y comenzamos a notar la diferencia que se sentía en nuestros corazones al recordar lo que vivimos ese día (Ruíz, Juana Alicia, comunicación personal, 2016).

El testimonio que viene a continuación describe las razones que llevaron a estas mujeres a elaborar el tapiz titulado "Día de llanto".

Ya nosotras habíamos aprendido lo que era el ciclo de violencia y cómo conmemorar después de haber sanado las heridas dejadas por el conflicto armado. Fue entonces cuando decidimos hacer una obra y llamarla "Mampuján 11 de marzo, día de llanto." En ese tapiz, cada una de nosotras se representó e hizo algo que le impactó de ese desplazamiento. Luego vino la sanidad del trauma, la rabia y el dolor, así como el tema del perdón la paz y la reconciliación (Valdés, Alexandra, comunicación personal, 2016).

Para las mujeres de Mampuján, el ejercicio de coser y conversar no solo generó espacios terapéuticos para la superación de traumas ocasionados por las secuelas dejadas por el desplazamiento, sino que también significó romper el ciclo de violencia apuntando sin duda alguna a la construcción de escenarios de paz.

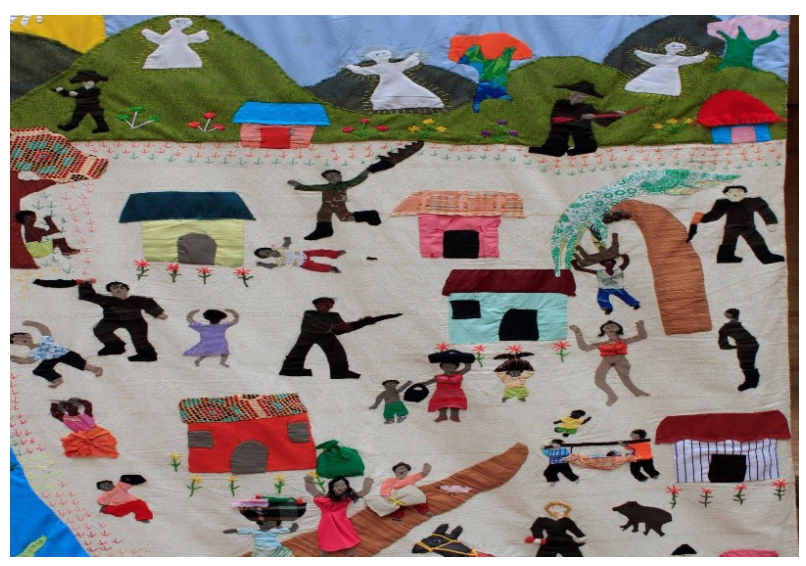

Fotografía 7. Desplazamiento

Fuente: (El Universal, 2017).

El desplazamiento masivo de la población de Mampuján tuvo un impacto decisivo en la historia personal y familiar de cada uno de sus pobladores. Este fenómeno social inscrito en la historia del conflicto armado en Colombia no fue ajeno a la subregión de los Montes de María. Sus repercusiones 
afectaron la autonomía económica de las comunidades dando paso a la dependencia, porque de dueños de tierras pasaron a vivir en albergues temporales y a tener que depender de la ayuda de otros, en este caso de los pobladores de María La Baja. En ese nuevo contexto, las entrevistadas narran las experiencias de vida y hacen énfasis en la forma en que les fue vulnerada su dignidad, y cómo el estigma comenzó a hacer parte de las relaciones de poder. En consecuencia, el trabajo de memoria les ha permitido tener un encuentro con momentos históricos de vida y vivencias personales y colectivas.

Es importante resaltar el papel que jugó la religión en este desplazamiento. Al observar más en detalle el tapiz "Desplazamiento", se pueden ver varios ángeles sobre las montañas bordeando el poblado. En los testimonios recogidos las entrevistadas explican que recuerdan haberlos visto esa tarde en que iban a ser asesinadas. Afirman que la decisión que tomaron los paramilitares de no asesinar a la población sigue siendo considerada por la comunidad como un milagro. Hay que señalar que alrededor de este acontecimiento se teje un discurso colectivo de poder y supervivencia a partir de una experiencia de fe.

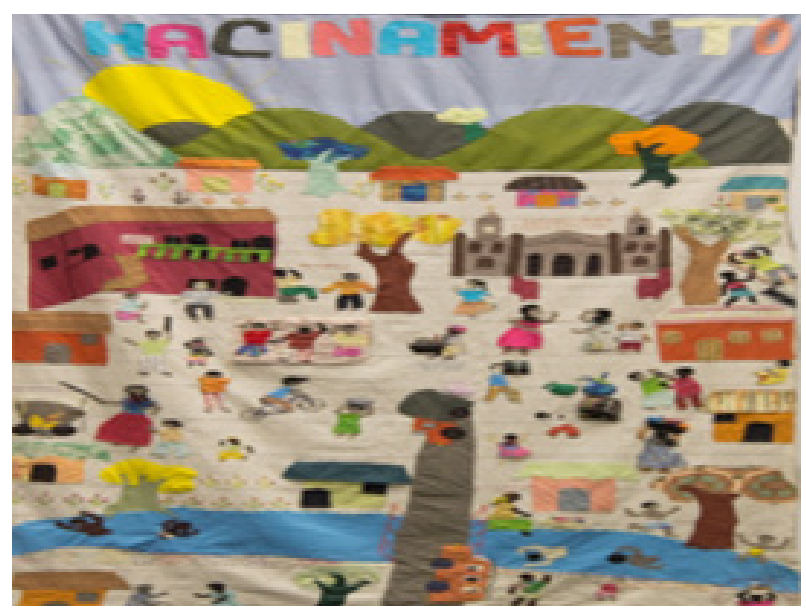

Fotografía 8. Hacinamiento

Fuente: (El Universal, 2017).

Este tapiz, recoge toda la experiencia de vida de los hechos que marcaron ese acontecimiento. Quisimos plasmar en él varios de los recuerdos de aquella tarde de horror en la que cada una tenía algo por narrar.
De esta forma, fuimos recordando en detalle cada escena. Por ejemplo, cómo iba vestido tal o cual persona ese día, a quienes tuvieron que transportar en hamaca porque se encontraban enfermos. Así como también, las personas que salieron corriendo de la plaza después que los paramilitares dieron la orden de desocupar el poblado. Pero, además, quisimos visibilizar lo que la mayoría de los que nos encontrábamos allí observamos esa tarde alrededor sobre los cerros que bordean el pueblo y que consistía en un grupo de ángeles que parecían custodiarnos (Valdés, Alexandra, comunicación personal, 2016).

En el tapiz titulado "Hacinamiento" las autoras plasman las difíciles condiciones en que vivían las 340 familias desplazadas de Mampuján al interior de los lugares que sirvieron de albergues temporales, entre estos las escuelas, la casa de la cultura del pueblo y casas donde anteriormente funcionaron prostíbulos. Esta nueva forma de vida trajo consigo el deterioro de las relaciones sociales, debido a los problemas de convivencia, así como afectaciones en la salud causadas por el estrés.

El tiempo en que vivimos hacinados afectó las relaciones. Antes del desplazamiento éramos muy unidos, como una sola familia. De lo que teníamos lo compartíamos, pero cuando empezamos a vivir en los albergues, comenzaron las peleas y los pleitos. En principio era por la comida, porque en ocasiones no alcanzaba para todos; otras veces, era por el baño, porque éramos tantos y teníamos que turnarnos y algunos no respetaban el turno. Al final la convivencia se volvió tan horrible que muchos optaron por no hablarse más entre ellos (Valdés, Alexandra, comunicación personal, 2016).

El tapiz denominado "Ma jende prieto" es una síntesis de los tapices descritos anteriormente. Cada cuadro representa un escenario histórico que evoca un pasado y una experiencia de vida contada en el presente, configurando un imaginario colectivo de voces que hablan por una comunidad silenciada frente al conflicto armado. En este contexto, la noción de temporalidad se construye a partir de las experiencias de vida de sus ancestros en dinámicas culturales que representan a una generación de africanos y africanas libres en su territorio y 
posteriormente capturados para ser comercializados como esclavos en América. En contraste, la resistencia y deseo de libertad ilustran el escenario del palenque, espacio en el que prevalece y se fortalece la identidad afrodescendiente. Asimismo, se observa en el tapiz, una comunidad de campesinos y campesinas asediados por el conflicto armado.
Por último, la escena en donde las expresiones y las emociones de los personajes se hacen visibles representando dinámicas que acompañan los procesos de retorno. Desde el año 2015 este tapiz se encuentra dentro del Museo Nacional, como parte de las obras de arte más representativas de la historia del país.

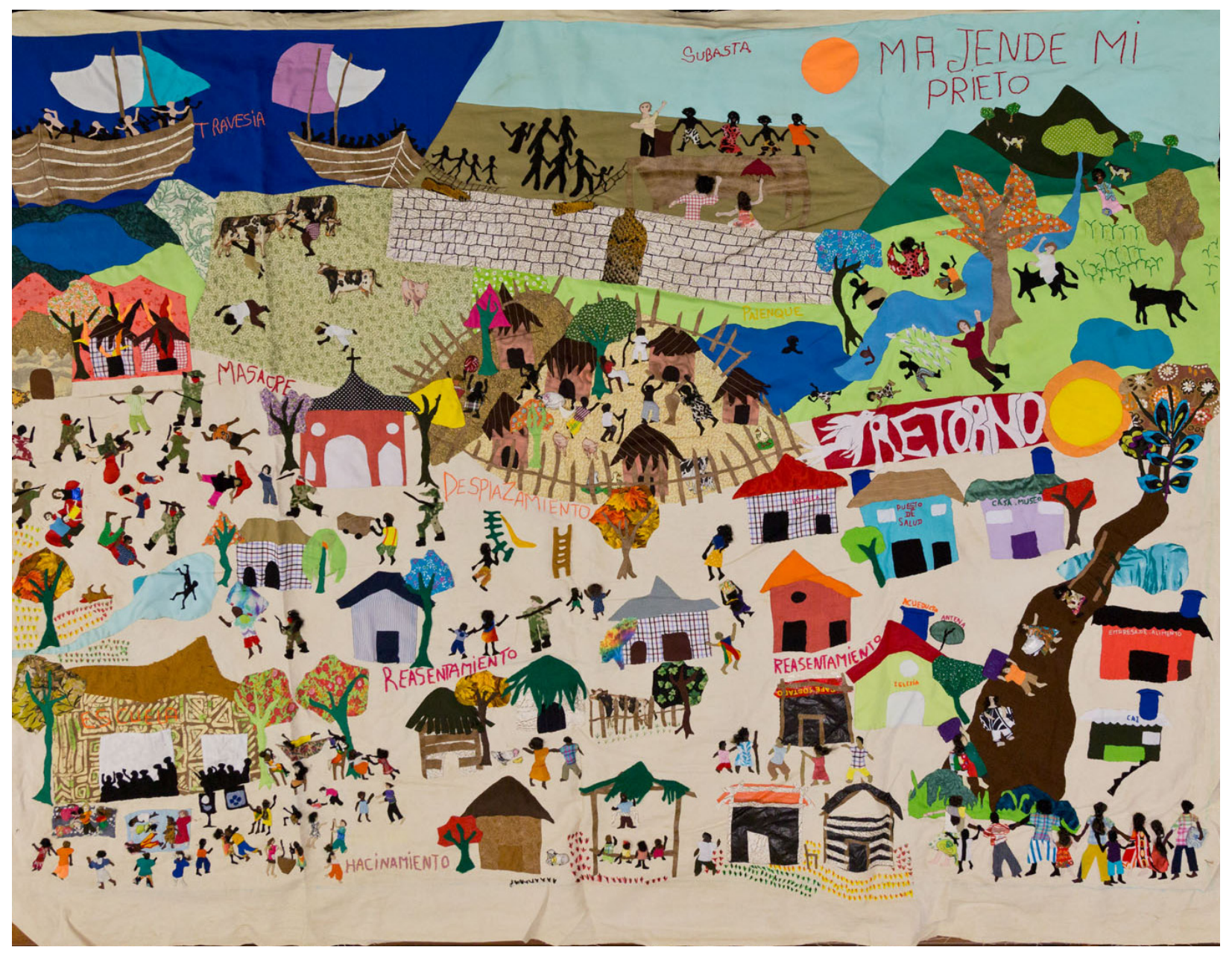

Fotografía 9. Ma jende mi prieto (Mi gente negra)

Fuente: (El Universal, 2017).

Este tapiz lo elaboramos en 2004 y ha sido donado al Museo Nacional. Cuando comenzamos a hacerlo, reflexionamos mucho acerca de nuestra historia y por eso decidimos llamarlo "Ma Jende Prieto", que en lengua palenquera, significa "Mi Gente Negra". En él, quisimos plasmar toda la historia de la travesía que pasaron nuestros ancestros desde África hasta llegar a estos pueblos de los Montes de María. Mostramos, además, la vida en los palenques y lo que ocurrió después cuando empezó a llegar a la comunidad gente que traía malas intenciones y comenzaron a hacer masacres y desplazamientos. También se plasmó el hacinamiento y el reasentamiento que es el lugar en dónde estamos ahora (Valdés, Alexandra, comunicación personal, 2016). 


\section{A modo de conclusión}

Este ensayo ha presentado la construcción de memoria colectiva vinculando tres elementos: el testimonio, la memoria y el género, con el propósito de analizar cómo las mujeres víctimas-testigo sobrevivientes del conflicto armado en Colombia se apropian de sus experiencias trágicas y las narran, logrando visibilidad y reconocimiento como sujetos históricos y de cambio en la sociedad.

Como experiencia testimonial al interior de este estudio se advierten unas memorias alternas y unas memorias emergentes, ligadas a lugares y artefactos que luchan por visibilizar sus experiencias individuales, familiares y colectivas frente a las memorias oficiales y académicas, que por criterios de selección emblemática permanecen silenciadas. Son memorias de víctimas-testigos-sobrevivientes del conflicto armado que están a la espera de ser escuchadas y reconocidas más allá de sus ámbitos locales, como sujetos de transformación social y de reparación colectiva memorias, que invitan a la acción solidaria y a generar espacios de reconciliación y denuncias dejando de lado, las fuentes generadoras de violencia y visibilizando, en este caso, las luchas de la mujer rural, afro, campesina en el proceso de construcción de la historia política, social y económica del país.

Estas técnicas de memoria se han convertido en un medio de sanación de duelo, a través de las cuales las víctimas logran expresar sus sentimientos y temores muchas veces silenciados en la cotidianidad. Tales inventivas abren espacios de solidaridad, denuncia y reconciliación en los que se genera un activismo político que conduce a la salida del sujeto mujer de esferas privadas a esferas públicas. En esos escenarios, el sujeto mujer participa, para protestar por los hechos ocurridos al interior del conflicto armado.

El tejido para las mujeres ha sido una labor cotidiana que les ha otorgado una identidad femenina, pero al mismo tiempo se ha convertido en una herramienta activa por medio de la cual las tejedoras expresan sentimientos de resistencia, emociones esperanza, libertad, opresión, diálogo. Por ejemplo, en la Grecia antigua, Penélope se vale del tejido para evadir a sus pretendientes, mientras espera el regreso de su esposo Ulises de la guerra de Troya. En Chile, durante la dictadura de Pinochet, las mujeres arpilleras transformaron aguja e hilo en un testimonio de lucha y resistencia política y al mismo tiempo, en un símbolo y una metáfora ${ }^{6}$. En Colombia las mujeres tejedoras de Mampuján han encontrado en el tejido, una herramienta para la sanación de duelo, construcción de la memoria colectiva y liderazgo dentro de su comunidad. Sus tapices, se han convertido en la práctica de un escenario generador de diálogo, reconocimiento individual y colectivo, también, en un artefacto para reconstruir una memoria dinámica y solidaria que genera espacios de recordación, denuncia y promoción de la verdad histórica del conflicto armado en el marco de una política para la construcción de paz.

\section{Referencias bibliográficas}

Agosín, Marjorie. (1985). Agujas que hablan: Las arpilleristas chilenas. Revista Iberoamericana, LI(132133), 523-529. doi: http://dx.doi.org/10.5195/ reviberoamer. 1985.4066

Barnet, Miguel. (1966, 1968). Biografía de un Cimarron. Barcelona: Ariel.

Beverly, John. (1987). Anatomía del testimonio. Revista de crítica literaria latinoamericana, (25), 7-16.

Burgos, Elizabeth. (1984, 2013). Me llamo Rigoberta Menchú y así me nació la conciencia. México: Siglo Veintiuno Editores.

Calveiro, Pilar. (2008). La memoria como futuro. Actuel Marx Intervenciones (6), 59- 70.

El Universal. (2017). Imágenes de mujeres de Manpuján. Recuperado de google.com.co: www.google.com.co/ search?q=imagenes + mujeres + de + mampuján\&rlz $=1$ C1CHZL_esCO745CO745\&source $=1 \mathrm{nms} \& \mathrm{tbm}=$

Hampâté bâ, Amadou. (1991). L'enfant peul. París: Actes-Sud.

Jelin, Elizabeth. (2002). Los trabajos de la memoria. España: Siglo XXI.

Lagarde, Marcela. (1997). Los cautiverios de las mujeres madresposas,monjas, putas, presas y locas. México: UNAM.

Lagarde, Marcela. (2012). El feminismo en mi vida Hitos, Claves y Etopías. Mexico: Instituto de las mujeres del Distrito Federal.

6 https://cienporcienhistoria.wordpress.com/2014/11/10/el-telar-y-la-mujer-en- 
Locke, John. (1999). Escritos sobre la tolerancia. Madrid: Luis Prieto Sanchís y Jerónimo Betegón Carrillo.

López-Baquero, Constanza. (2012). Trauma, memoria y cuerpo: el testimonio femenino en Colombia (19852000). Estados Unidos: Asociación Internacional de Literatura y Cultura Femenina Hispánica (AILCFH).

Montaño, John. (18 de Noviembre de 2015). El conmovedor relato de las mujeres que ganaron el nacional de paz. El Tiempo.

Moro, Tomás. (1941). Utopía. (C. Roquette de Fonvielle, Trad.) Buenos Aires: Sopena Argentina.

Navia, Carmiña. (2005). Guerras y paz en Colombia: Las mujeres escriben. Cali: Universidad del Valle.

Nora, Pierre. (1984). Entre memoria e historia A problemática dos lugares (Vols. XVIII-XLII). (Y. A. Khoury, Trad.) Paris, Gallimard: Departamento de Historia, PUC-SP Saou Paulo. Recuperado de https:// revistas.pucsp.br/index.php/revph/article/viewFile/12101/8763.

OHCHR. (2013). Los estereotipos de género y su utilización. Naciones Unidas Alto Comisionado. Recuperado de: https://www.ohchr.org/sp/issues/women/wrgs/ pages/genderstereotypes.aspx

Ruíz-Hernández, Juana Alicia. (2013). Vivensías narraciones comunitarias de la historia, los aprendizajes y el desarrollo de la ruta jurídica en el marco de la sentencia 34547 de Justicia y Paz, a partir de las experiencias de Mampuján. Estados Unidos: Departamento de Justicia.

Sánchez Blake, Elvira. (2000). Patria se escribe con sangre. Barcelona: Anthropos Editorial.
Sánchez Blake, Elvira. (2012). De actoras armados a sujetos de paz: Mujeres y reconciliación en el conflicto colombiano. Revista La manzana de la discor$\operatorname{dia}(7), 7-13$.

Sánchez Blake, Elvira. (2016). La ruta pacífica de las mujeres: repertorios simbólicos en la búsqueda de paz y reconciliación en Colombia. Revista Colombiana de Educación (71). Recuperado el 17 de Noviembre de 2017, de http://www.scielo.org.co/pdf/rcde/ n71/n71a12.pdf

Scott, Joan. (1986). El género: una categoría útil para el análisis histórico. American Historical Review, 91(5), 1053-1075. doi: https://doi.org/10.1086/ ahr/91.5.1053.

Todorov, Tzvetan. (2000). Los abusos de la memoria. Barcelona: Paidós.

Vásquez, María Eugenia. (2000). Escrito para no morir: bitácora de una militancia. Bogotá: Ministerio de Cultura.

Verdad Abierta. (2015). Contexto histórico y sociológico del desplazamiento de Mampuján. Verdad Abierta.

\section{Fuentes primarias}

Ruíz, Juana Alicia (2016) Lideresa asociación Mujeres Tejiendo Sueños y Sabores de Paz de Mampuján, Mampuján Nuevo (Jokabel Ramos Díaz Granados, entrevistadora).

Valdés, Alexandra (2016) integrante asociación Mujeres Tejiendo Sueños y Sabores de Paz de Mampuján, Mampuján Nuevo (Jokabel Ramos Díaz Granados, entrevistadora). 


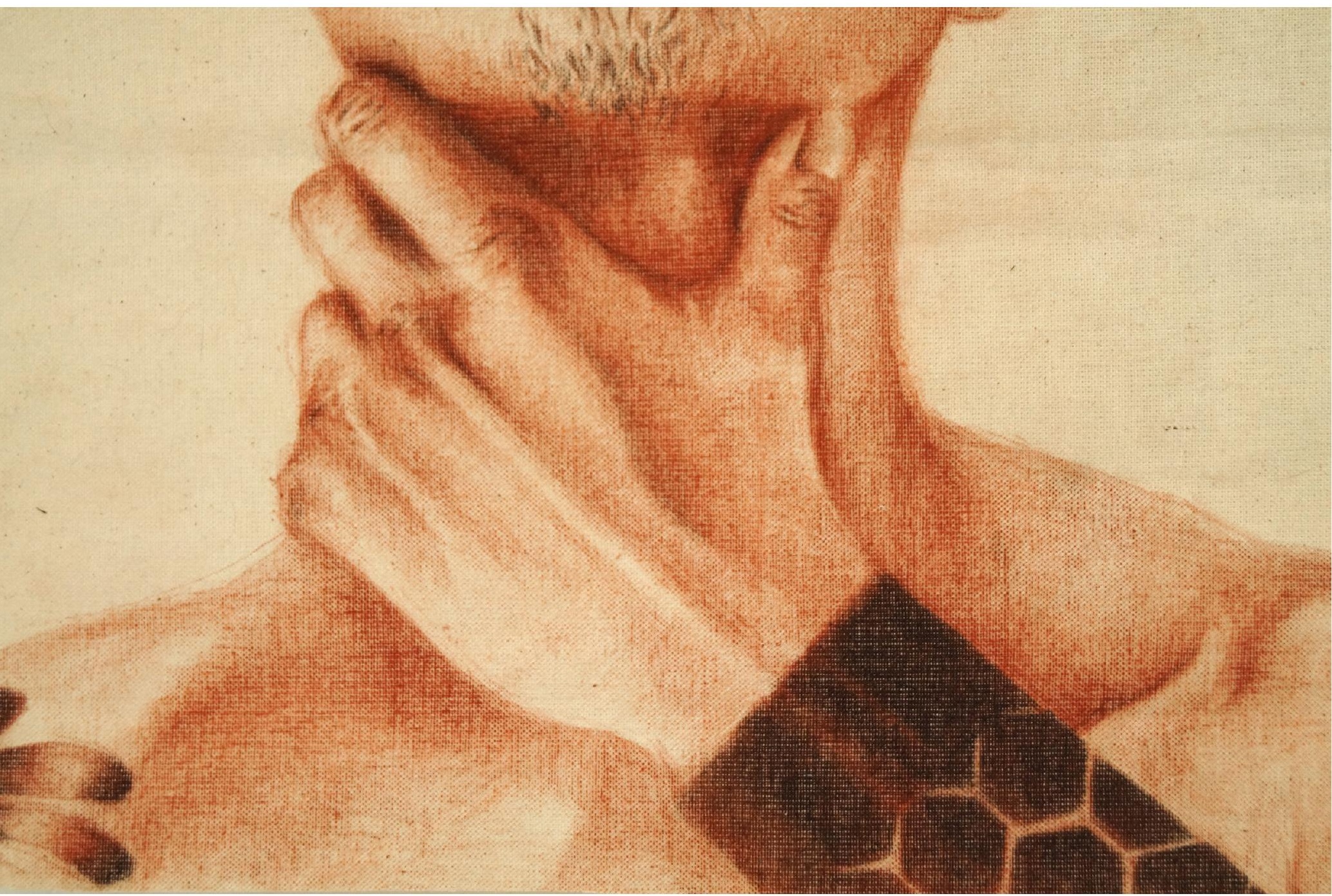

Imagen 3. Sin título (de la serie TRANS-ANATOMÍA)

Dimensiones: 43 x $47 \mathrm{~cm}$

Técnica: Lápices sanguina y sepia sobre lienzo

Año: 2018

Autor: Alie Galindez Poveda 